\title{
We Didn't Deserve This: Bereavement Associated with Multifetal Reduction
}

\author{
Kate Sullivan Collopy \\ Department of Nursing, University of New Hampshire, USA
}

\begin{abstract}
W th the dramatic increase in the incidence of higher-order multiple pregnancies, more and more women are advised to consider undergoing multifetal reduction. However, little is known about the woman's experience of making the decision to undergo or forgo reduction. This study explored the experiences of seven women in making this decision and to identify any effects of it. Vivid descriptions emerged of multiple levels of bereavement. Several participants lamented that nothing occurred naturally in their pregnancies, from conception right through delivery and life with multiples.
\end{abstract}

Throughout much of the world, advances in infertility treatment have resulted in an explosive rise of multifetal gestations (Imaizumi, 1998). Since the incidence of maternal and fetal morbidity and mortality increases with each additional fetus, couples are often advised to consider a multifetal reduction of pregnancies with three or more fetuses in order to improve the pregnancy outcome.

Despite the wide use of multifetal reduction, there has been scant research on the experiences of the women themselves. Therefore, the aims of this study were to explore the decision-making experience of women who were offered the option of multifetal reduction for their higher order multiple pregnancies and to identify any effects on women from making decisions to undergo or forgo multifetal reductions. Specifically, this paper focuses upon the bereavement associated with infertility and multifetal reduction.

\section{Materials and Methods}

Seven women who conceived higher order multiple pregnancies as a result of in vitro fertilization (IVF) were interviewed between 9 months and 4 years after the completion of their higher order multiple pregnancy.

The primary interview lasted between 60 and 90 minutes and was deliberately unstructured so as to avoid directing the participants (Munhall, 1994). Participants were asked "What was the experience like to make the decision whether or not to reduce your pregnancy?". A follow-up interview took place between 1 and 12 weeks later which allowed time for reflection. A final interview was undertaken to discuss the findings.

Data was collected and analyzed using Van Manen's approach. (Van Manen, 1990, pp. 30-31).

Of the 7 participants, 4 conceived triplets, 2 conceived quadruplets (with one set spontaneously reducing to triplets), and 1 conceived quintuplets (with a spontaneous reduction to quadruplets). Two women declined to reduce triplets, 1 declined to reduce quadruplets, 3 women elected to reduce from 3 fetuses to 2 , while one woman chose to reduce from 4 to 2 .

Of the 4 women who reduced their pregnancies, 3 delivered healthy twins, while 1 lost the complete pregnancy within 2 weeks of the reduction. Of the 3 women who chose not to have a reduction, 1 delivered healthy triplets, 1 delivered healthy quadruplets, and 1 lost her triplets at 20 weeks. Both of the women who lost their pregnancies subsequently became pregnant with multiples again, delivering twins and triplets. These 5 children are all alive and well. (see Table 1)

\section{Results}

Details of the participants' reproductive history are given in Table 2. None had any previous living children.

Five main themes emerged from the interview data: 1) a single-minded, relentless pursuit of conception; 2) powerful emotions on receiving the diagnosis of a higher order multiple pregnancy - ranging from concern to euphoria; 3 ) the difficulty of making a life-altering decision quickly; 4) the experience of sustaining multiple types of losses while attempting to become mothers; and 5) the lasting effect of the decision.

An unexpectedly wide variety of losses were described going back through their childbearing years and a realization that most of these losses were invisible to others, heightening the women's sense of being alone in their grief.

The first loss for each woman had been the recognition of infertility, depriving them of years of parenting, the ability to plan the timing and size of their families and the joy of conceiving. They lost confidence in their own body. Two participants wondered whether this had affected their decisions to risk multiples by having more embryos transferred:

In retrospect, I don't know if I would've, if I had kind of had enough confidence in myself, I might have done three [instead of four]. But, at the time you just don't

Address for correspondence: Kate Sullivan Collopy, Department of Nursing, University of New Hampshire 257 Hewitt Hall, Durham, New Hampshire, 03824,USA. Email: kate.collopy@unh.edu 
Table 1

Outcome of Pregnancy

\begin{tabular}{lccc}
\hline Participant & $\begin{array}{c}\text { Gestational Age } \\
\text { at Delivery }\end{array}$ & Type of delivery & Outcome of This Pregnancy \\
\hline Christine & 38 & Cesarean & Twins alive and well \\
Sheila & 36 & Cesarean & Triplets alive and well \\
Holly & 20 & Vaginal & No surviving children \\
Kim & 38 & Cesarean & Twins alive and well \\
Helen & 37 & Cesarean & Twins alive and well \\
Emma & 32 & Cesarean & Quads alive and well \\
Angela & 17 & Dilatation and Extraction & No surviving children
\end{tabular}

Table 2

Description of the Sample

\begin{tabular}{|c|c|c|c|c|c|c|}
\hline Participant & $\begin{array}{l}\text { Years of } \\
\text { Infertility } \\
\text { Treatment }\end{array}$ & $\begin{array}{c}\text { Previous } \\
\text { Pregnancies }\end{array}$ & $\begin{array}{c}\text { Embryos } \\
\text { Transferred }\end{array}$ & $\begin{array}{c}\text { Original } \\
\text { Number of } \\
\text { Fetuses }\end{array}$ & $\begin{array}{l}\text { Spontaneous } \\
\text { Reduction }\end{array}$ & $\begin{array}{l}\text { Multifetal } \\
\text { Reduction }\end{array}$ \\
\hline Christine & 2 & None & 4 & 3 & No & From 3 to 2 \\
\hline Sheila & 5 & Loss at $18 w k$ & 3 & 3 & No & Declined \\
\hline Holly & 3.5 & 2 miscarriages & 4 & 3 & No & Declined \\
\hline Kim & 1 & None & 9 & 4 & 1 fetus & From 3 to 2 \\
\hline Helen & 4 & 1 miscarriage & 6 & 3 & No & From 3 to 2 \\
\hline Emma & 1 & Stillbirth & 5 & 5 & 1 fetus & Declined \\
\hline Angela & 3 & 1 miscarriage & 6 & 4 & No & From 4 to 2 \\
\hline
\end{tabular}

have... I mean I had never been pregnant before in my life. (Christine)

While the participants knew that there was a risk of conceiving multiples with IVF, each of them believed that, "it can't happen to us." The combination of needing infertility treatment, enduring multiple treatment failures and, in some cases, previous pregnancy losses left most of them feeling there was no way that they could have a problem with hyperfertility. Each participant was stunned with the diagnosis of a higher order multiple pregnancy and most were ill prepared to deal with the decision of whether or not to undergo reduction.

\section{Relationships with Others}

It was also clear that the experience of being infertile changed many of the relationships that the participants had with their family and friends. The support that the women initially enjoyed began to wane over time:

The first year was great! I mean, a lot of people I had support of, you know, my family and my friends, but as you go through it, the longer you go through it, it kind of gets old and it's not as important in their life. (Holly)

When the participants were deciding about reduction they often felt isolated and alone.

Helen came to realize that if many people knew that she had undergone multifetal reduction, they might disclose this to her twins before she and her husband were ready to tell them:

We ended up not telling a lot of people because we decided that this is my children's story, this is their history and they should find out first and not have someone come up to them someday. Who knows how that would happen, but someone might say, 'by the way, we do know there were three of you' or make some slip. (Helen)

\section{It's Not the Same}

Most of the women in the study had been pursuing pregnancy for several years and had so looked forward to hearing the incredible news that they were, at last, pregnant. Yet due to the conception of high multiples they had immediately to face the reduction dilemma:

Here you are and you get this heavy burden and you walk out that door and you are supposed to be happy about it? I mean, I didn't have a chance to really enjoy it, the fact that you were going to have a baby. It was like, a lot of decisions to be made and thinking about what could happen. And I know that's a fact of carrying multiples, it's not the same as a singleton pregnancy that you can walk out and really be, you know happy. There were just so many concerns that it kind of put a damper on the whole thing and even the whole suggestion of selective reduction was really sad. Because this [becoming pregnant] is what you wanted! (Holly)

For Helen, the combination of past miscarriages and uncertainty left her trying to steel herself against yet another loss: 
I was really in denial the whole time we were even pregnant. We had so many losses and I just... and then of course the whole nightmare of the selective reduction decision and procedure it was like there was no joy in this and surely this is all just going to fall apart and we're not going to have anything. (Helen)

\section{Am I Doing the Right Thing?}

Of the 4 participants who elected to undergo multifetal reduction, 3 said the decision and the procedure caused intense heartache and suffering. Several weeks were spent hoping that a spontaneous reduction would occur and eliminate the need for the procedure.

I kept thinking, and kind of hoping... that one of them, might happen and I didn't have to do [a reduction], it would just kind of naturally... and it didn't. (Holly)

Christine recalled being told that "one of the triplets might dissolve, so I was like, 'Oh, please, let it be natural!' I just really wanted one thing in the whole thing to happen naturally."

During the reduction, several women experienced unexpected pain or distress that left them questioning their decision to reduce. During Christine's reduction procedure she experienced pain:

I was just like, "Oh my God, I've gotta stop!" and I doubled over in pain. And I started crying. And it was from the pain; it was clearly not the procedure that made me cry... And of course at that point, I was like, "Am I doing the right thing? Maybe I am doing the wrong thing. Is this a sign? Like we should stop?" And, but, we kept going... knowing that it was going to be painful, probably more emotionally than physically. (Christine)

Even after her reduction, Helen felt a strong connection to the fetus that was reduced. For the first few weeks after the procedure she used a Band-Aid to help her maintain her bond:

They had the Band-Aid on where the needle had gone in and they said you could take off the Band-Aid that day. I couldn't take off the Band-Aid. I left it on for like two weeks because I wanted to know where the baby was and that marked where the baby was and I could put my hand on it and talk to it. (Helen)

A few weeks later, Helen found herself in a position where she was able to let go. She went to her obstetrician for a routine follow-up:

When I had my shirt up for the ultrasound and he asked, 'What's this Band-Aid doing here?'And I said, 'That's where the dead baby is.' And he just kind of looked at me and I said, 'Well, I just want to leave it there'and he said that he needed to take if off to do the ultrasound. And so that was the first time I had to make this conscious decision that it was coming off. And I said that I just wanted to know where it is and he said that he could put another Band-Aid on it after I get done. And it was kind of like by him taking it off, I didn't have to make that choice. And then after the ultrasound, he was going to [put a Band-Aid back on] and I said that it was okay and that he could leave it off now. (Helen)
Angela had the feeling that her health care team never cared about her or her pregnancy. "The whole way around, they just treated it so matter-of-factly, like it wasn't a baby, like it was just like, 'OK, we've got to get rid of these two'".

The day of the reduction was the first time that Angela had seen a detailed sonogram of the fetuses. Disturbingly the room was set up so that she and her husband would watch the entire reduction procedure:

It was horrible, horrible!... that was the first time I really saw the babies and, I mean, a 12-week-old baby looks like a fully born baby!

...And then we went ahead with the second one and that was worse because they missed the first time. They had to do it again! Terrible! And you watch the whole thing on the screen. It was just a horrible experience. (Angela)

In spite of her terribly difficult reduction, Angela said, "We were OK afterwards. Cause we knew we had made the decision and we knew that we had made it the right way...for us at the time."

\section{Don't Want Pictures}

Christine was very aware that her pregnancy was different and the sonograms represented this difference:

Yeah, there were so many sonograms. They lost their everyone's like, 'Oh, you're getting a sonogram! Get pictures!' I was like, no thanks. I don't want pictures. I'll get pictures when they're born. It lost a lot of its fun. I still get icky when I see other people's sonogram pictures. I just... you know? It's so easy for some people. They get pregnant on a dime, perfect child, there's nothing wrong with them. They...show all the pictures and, you know, they don't know how good they have it! (Christine)

At 18 weeks Helen had an ultrasound technician who was unfamiliar with reduction. The technician's insensitivity had a lasting effect. As the examination began:

I explained I had a selective reduction and that there were triplets so when you get to this side, you may come across that baby. 'Well, why would you do that?' And I just, all of a sudden, I just sank. And here I had to be there for an hour with this person who kept questioning and I felt like I was justifying my decision. (Helen)

As the procedure continued, Helen's frustration mounted:

So she's doing the ultrasound on Baby A... which goes on to the videotape and then she's doing Baby B and then she says we have to measure Baby C... 'What did you call that again?'... and so she typed on the screen 'selective reduction'... I'm never going to look at that videotape... Why would she even need to measure this baby? (Helen)

\section{Lack of Information}

Two participants miscarried during the second trimester. For Angela and her husband, one of the most difficult aspects was not having enough information:

Nobody really presented the downside of the fetal reduction. They presented it that there was a $5 \%$ chance of losing the whole [quadruplet] pregnancy, but nobody really said 'This is a very real risk,' and it's a lot more than $5 \%$. 
This I know from talking to people afterward. But no one really said that to us. (Angela)

Following this loss, Angela resumed treatment for infertility. Her tragic experience did not lead her to transfer fewer embryos. She and her husband chose to transfer seven embryos, saying she wanted to, "to increase my odds of just getting pregnant." Again, she conceived quadruplets. This time she declined to reduce. One fetus spontaneously reduced and was reabsorbed. Angela went on to have a healthy set of triplets.

Holly suffered the loss of her triplets at 20 weeks gestation. For nearly a week she complained of contractions and bloody vaginal discharge. She recalls being told "with triplets that happens":

Had they had me come in then it could have been different. Maybe not... I feel they were so nonchalant about a pregnancy that was supposed to be so high risk... You lose a little bit of faith in the medical profession. (Holly)

For her physicians, delivering at 20 weeks was seen as an early loss. But Holly's perception was that her loss came quite late in the pregnancy:

I had a miscarriage at 11 weeks and, I mean, I was upset, it was hard, but it wasn't the same as at 20 weeks... there I had to go through the whole birthing process to come out with nothing! To walk out of that hospital, just with a box of memories and that was it. (Holly)

Unlike Angela, when Holly resumed her treatment she and her husband were very frightened of conceiving higher order multiples again. Although three were recommended she was adamant that only two embryos be transferred. Following her very next IVF cycle Holly conceived twins. Although born quite small she was able to take home two healthy babies.

Each of the participants grieved that nothing came "naturally" to them; their conceptions, their pregnancies and their (caesarean section) deliveries.

\section{Painful Reminders}

Most of the time the participants were able to spend their days enjoying life and enjoying their children. Yet each of the five women who had had a loss either through multifetal reduction or miscarriage said they were regularly reminded of their losses, through anniversaries

"I think anniversaries of losses hit people emotionally. All of a sudden I'm looking, I'm just looking at Wendy [one of her twins] and thinking, it could've been her."

These five participants recalled their decision about reduction whenever there were any high-profile cases of higher order multiples in the media. For Holly, who lost her triplets at 20 weeks, the birth of the McCaughey septuplets was particularly disturbing.

... she can carry seven babies and I can't even carry three?... She didn't reduce and she had seven and she was all right. And, I didn't reduce and I only had three and I lost all three of them... (Holly)

One of the reasons that Helen chose to reduce was that she was not sure that she would be able to give three babies the amount of attention and care that they required to thrive. Therefore, stories about the McCaughey's were particularly upsetting for her:

And still I get mad now too, being a twin mom and knowing how hard it is by myself, when I saw a '20/20' [television] interview with the McCaughey septuplets on their first birthday. When she was talking, her eight-hour-anight-sleep she got the night before because they have these church people coming in 24 hours a day. And I was like, 'Yeah, gee that would be nice'. (Helen)

At the time of the interview, there was no public indication of the disabilities from which some of the septuplets now suffer.

The two participants who declined reduction and delivered healthy triplets and quadruplets were immensely satisfied with their decisions and had no second thoughts about it. Yet both of them had thought many times about which child(ren) might have been reduced. Sheila knew exactly which one of her children would have been lost. Loving this child made it difficult to think about what their lives would have been like had they chosen to reduce.

\section{Discussion}

The decisions to undergo reduction or maintain a higher order multiple pregnancy had a lasting impact on the women. For those who chose to reduce, they grieved about the child or children who might have been while those who declined to reduce wondered about which one of their children would not be with them if they had undergone reduction. This was consistent with other studies of psychological reactions to multifetal reduction (McKinney et al., 1996; Schreiner Engel et al., 1995).

Viewing an ultrasound examination is likely to increase the value of the fetus for parents who already greatly long for a child. It may act as a powerful stimulus for maternal-fetal attachment making the question of reducing any fetus all the more difficult particularly with the prospect of continuing a pregnancy with a dead fetus(es) along side a live one(s).

These findings clearly illustrate the need for improvement in the initial as well as later care of women who conceive iatrogenic multiples including recognition of the multiple types of loss associated with infertility. The yearning for a child sometimes leads to increased risk-taking regarding the number of embryos transferred and this raises disturbing ethical questions.

In addition, these women are at risk for depression because of their losses. Experienced mental health staff should be part of a multidisciplinary approach to care of the infertile. Practitioners should not assume that successfully bearing children cures the grief associated with infertility or reduction. Staff must be educated properly about the procedure and patients should never have to justify their decisions.

Finally, physicians must ensure that the woman and her partner are given complete and understandable information regarding the pregnancy options. 


\section{$\overline{\text { Acknowledgments }}$}

This study was funded in part by grants from the National Institute of Nursing Research and Sigma Theta Tau (Eta Iota Chapter).

\section{References}

Imaizumi, Y. (1998). A comparative study of twinning and triplet rates in 17 countries, 1972-1996. Acta Geneticae Medicae et Gemellologiae (Roma), 47(2), 101-114.

McKinney, M. K., Tuber, S. B., \& Downey, J. I. (1996). Multifetal pregnancy reduction: Psychodynamic implications. Psychiatry, 59, 393-407.
Munhall, P. L. (1994). Revisioning phenomenology: Nursing and health science research. New York, NY: National League for Nursing Press.

Schreiner Engel, P., Walther, V. N., Mindes, J., Lynch, L., \& Berkowitz, R. L. (1995). First-trimester multifetal pregnancy reduction: Acute and persistent psychologic reactions. American Journal of Obstetrics and Gynecology, 172, 541-547.

Van Manen, M. (1990). Researching lived experience: Human science for an action sensitive pedagogy. New York, NY: State University of New York Press. 